\title{
Stimulation of motor tracts in multiple sclerosis
}

\author{
A BERARDELLI. M INGHILLERI, G CRUCCU, M FORNARELLI, \\ N ACCORNERO, M MANFREDI
}

\author{
From the V Clinica Neurologica, Dipartimento di Scienze Neurologiche, Università degli Studi "La Sapienza", \\ Rome, Italy
}

SUMMARY Percutaneous electrical stimulation of the motor cortex was used to evaluate corticospinal conduction to upper-limb motoneurons in 29 patients with multiple sclerosis. Central motor conduction abnormalities were correlated with clinical signs and somatosensory evoked potentials. Muscle responses to cortical stimulation were altered in 20 patients. The most common abnormality was increased central motor conduction time; in two cases the responses to cortical stimulation were absent. Abnormalities were also present in patients with no clinical evidence of corticomotoneuron deficit. Alterations of muscle responses and of somatosensory evoked potentials were usually correlated, but may appear independently. Both testing methods are useful in the study of patients with multiple sclerosis.

In 1980 Merton and Morton ${ }^{1}$ described a technique of bipolar electrical stimulation of the motor cortex in the intact man which produces contraction in the contralateral limb muscles at a latency compatible with the activation of fast corticospinal axons. Stimulation of the cervical region with the same technique activates the muscles at a shorter latency. The central motor delay can be calculated by subtracting the latencies of responses evoked at the two sites of stimulation. ${ }^{2-3}$

With this technique a slowing of central motor conduction along the cortico-spinal tract has been described in patients with multiple sclerosis, ${ }^{4-6}$ focal cerebrovascular damage ${ }^{78}$ and motor neuron disease. ${ }^{8-10}$ In multiple sclerosis ${ }^{11}$ an increase of central motor delay has been also recorded using the technique of unipolar anodal stimulation ${ }^{12}$ and with percutaneous magnetic stimulation ${ }^{1314}$ of the motor cortex. With the technique of bipolar electrical stimulation $^{1-3}$ we have now studied the changes of central motor conduction time in patients with multiple sclerosis and compared these with the abnormalities of the somatosensory evoked potentials and to clinical sensorimotor impairment. Address for reprint requests: Dr A Berardelli, V Clinica Neurologica,
Viale dell'Universita in.30, 00185 Rome, Italy.

Received 4 August 1987 and in revised form 31 December 1987. Accepted 5 January 1988

\section{Material and methods}

The study was performed in 29 patients ranging in age from 21 to 54 years (mean age 32 years) and in 15 normal subjects including the authors, of similar age (range 20-55 years, mean age 34 years) and height. Informed consent was obtained and the study was approved by the local ethical committee.

The patients were classified, according to McAlpine's criteria (1972), into definite (20 cases, table 1) and non definite (probable and possible) multiple sclerosis (9 cases, table 1). Sensory and motor functions of the upper limbs were evaluated by an independent examiner, without knowledge of the result of electrophysiological investigation. Increased tone and hyperreflexia were considered indicative of "pyramidal signs". When present the weakness was mild and was assessed grade 4 ("Aids to the Examination of the Peripheral Nervous System, Medical Research Council"). Sensory involvement was demonstrated by impairment of sharp and dull discrimination, vibratory stimulus recognition and movement and position perception. Details of the patients and motor and sensory clinical signs in the upper limbs are summarised in table 1; "Past" indicates sensory motor impairment in the history. Electrical stimulation of the motor cortex and cervical region was carried out with a Digitimer model D180 stimulator supplying a maximum of $750 \mathrm{~V}$ with a time constant of 50 or $100 \mu \mathrm{s}$. Cortical stimulation was performed with surface electrodes, the cathode being on the vertex and the anode $7 \mathrm{~cm}$ down on a line between the vertex and the external auditory meatus. For cervical stimulation the surface electrodes were placed on the midline, with the cathode over the processes of $\mathrm{C} 7$ and the anode $5-6 \mathrm{~cm}$ above.

The muscle action potentials evoked by stimulation of the motor cortex (cortical MAPs) and cervical region (cervical 
Table 1 Patients with definite multiple sclerosis

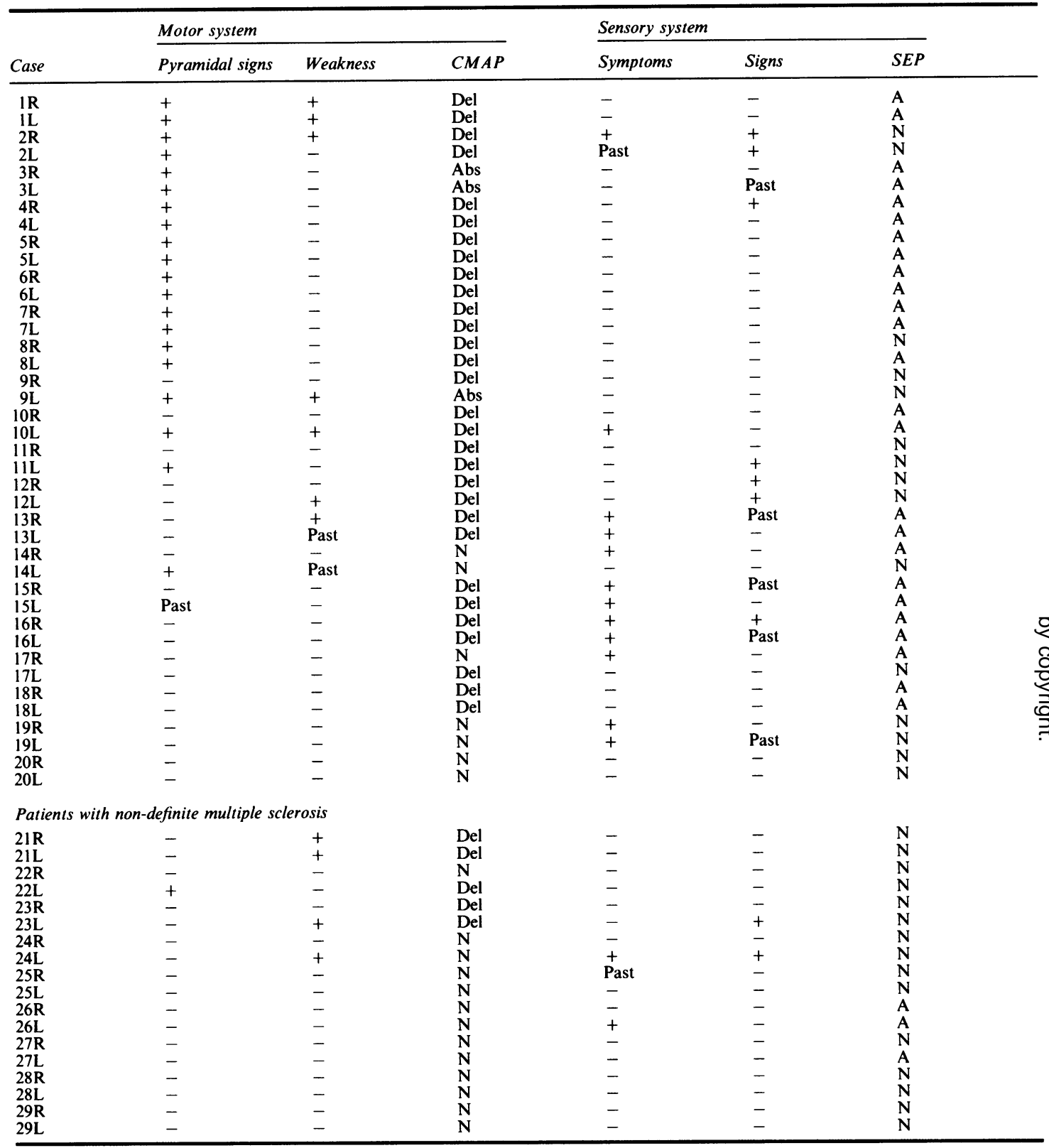

MAPs), were recorded by surface electrodes from biceps and thenar muscles. EMG signals were amplified, filtered ( $3 \mathrm{db}$ at $5000 \mathrm{~Hz}$ ) and stored for off-line analysis by means of a Biopotentials Analyzer Software Interactive System (BASIS, OTE). Four to six responses, evoked at a 5-10s interval, were recorded. Cortical MAPs were collected during a background voluntary contraction of the target muscle equal to approximately $10 \%$ of their maximum force. Contraction facilitates the EMG responses. ${ }^{2-3}$

Since cervical MAPs are not influenced by voluntary muscle contraction ${ }^{2}$ cervical stimulation was carried out at rest. The intensity of stimulation was adjusted by selecting the voltage which produced the shortest response latencies.

Latency of MAPs was measured from the stimulus artifact to the onset of the response. The four shortest responses were selected and averaged. The duration of MAPs was 
measured from the beginning to the end of the muscle potential. Central motor conduction time (CMCT) was calculated by subtracting the mean latency of the cervical MAPs from the mean latency of the cortical MAPs. This value is independent from upper limb length.

MAPs were considered abnormal when the responses were absent or when the latency or CMCT exceeded the upper limits of the normal range in at least one muscle. MAPs were also considered abnormal when the duration exceeded the upper range of normal values.

The somatosensory evoked potentials (SEPs) were obtained by separate stimulation of the median nerves on the two sides, and recorded with electrodes placed over the brachial plexus at Erb's point, on the posterior neck at the level of the seventh cervical spine and on the contralateral parietal scalp ( $2 \mathrm{~cm}$ posterior to the $\mathrm{C} 3$ or $\mathrm{C} 4$ locations). A common reference electrode was placed on the ear lobe contralateral to the side of stimulation. The median nerve was electrically stimulated at the wrist at a rate of $3 \mathrm{~Hz}$ with pulses of $0.1 \mathrm{~ms}$ duration, at an intensity slightly above motor threshold. Two or three series of 500 responses were averaged and stored on BASIS equipment.

The following SEP data were examined: Erb-point potentials, N13 of the cervical spinogram, N20 of the cortical signal. The latency difference between N20 cortical potential and the Erb's point potential was taken as a measure of central sensory conduction time (CSCT). Neither CMCT nor CSCT depend on upper-limb length. SEPs were considered abnormal when one of the responses was absent or the CSCT conduction time exceeded the upper range of normal value.

Differences of neurophysiological results between patients and normal subjects were statistically evaluated by Student's $t$ test. Clinical-neurophysiological correlations were assessed by chi-square test: the proportion of arms with a physical sign and abnormal neurophysiological values were compared with the proportion of arms with a physical sign and normal neurophysiological values.

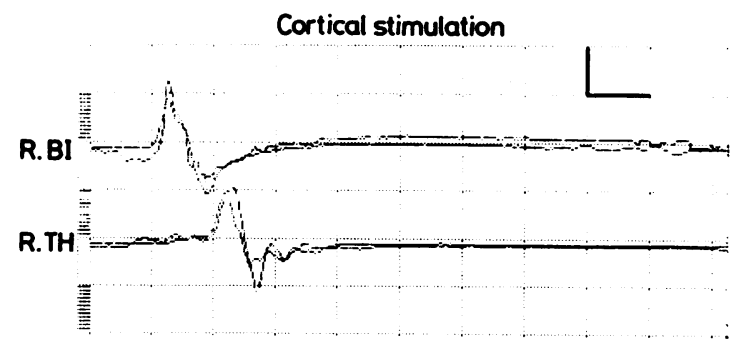

\section{Cervical stimulation}

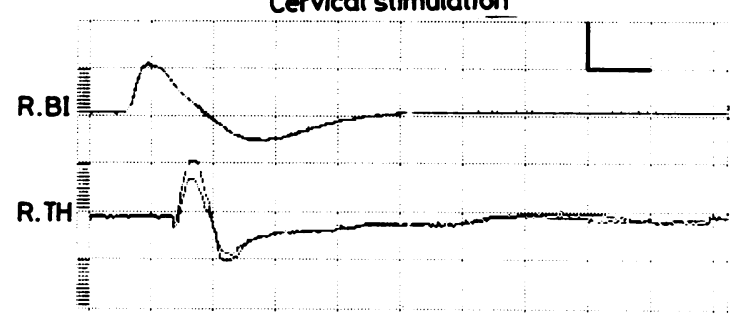

Fig 1 Muscle action potentials (MAPs) after cortical and cervical stimulation in a normal subject. $R$.BI. (right biceps), R.TH. (right thenar). Superimposition of two single potentials. Horizontal calibration $10 \mathrm{~ms} /$ div, vertical calibration $1 \mathrm{mV}$ for the cortical MAPs and $2 \mathrm{mV}$ for the cervical MAPs.

\section{Results}

\section{Motor responses}

Cortical and cervical stimulation evoked MAPs in all control subjects (fig 1). The latency of the cervical and cortical MAPs was similar to that already reported ${ }^{79}$ (table 2). The duration of the MAPs was 19.0, SD

Table 2 Latency of motor responses to cortical and cervical stimulation (mean, SD)

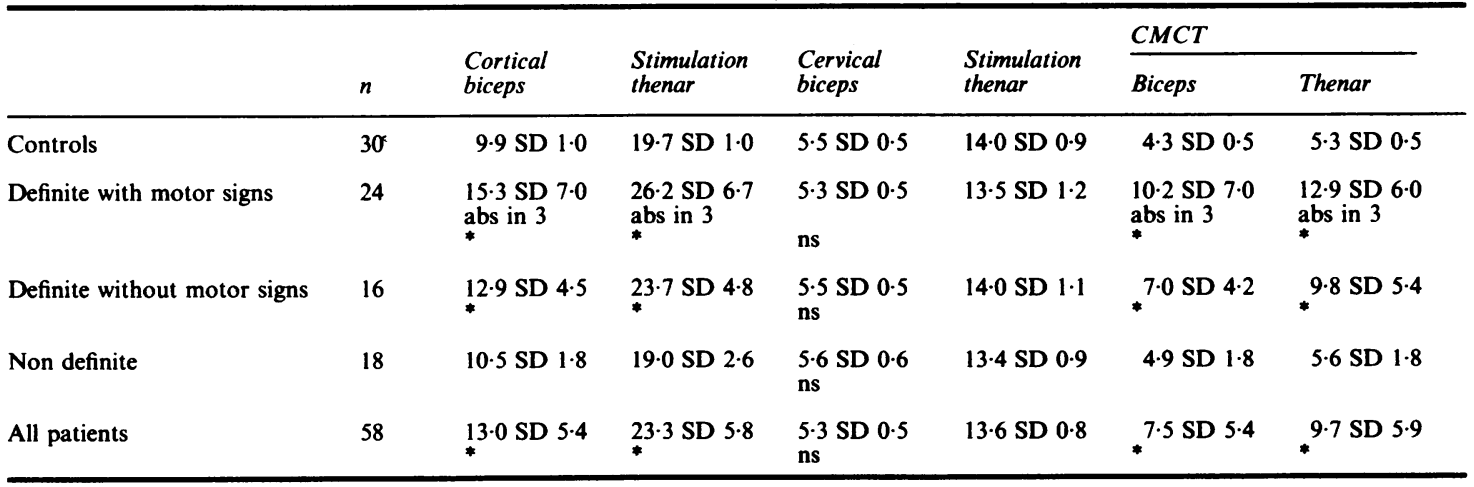

CMCT: Central motor conduction time.

$\mathrm{n}$ : number of examined arms.

*: statistical significance refers to difference between controls and each of the patient groups (Student's $t$ test).

$\mathrm{p}<0.01$. 
$7.0 \mathrm{~ms}$ for the biceps and $18 \cdot 2, \mathrm{SD} 6.5 \mathrm{~ms}$ for the thenar muscles on cortical stimulation and $22 \cdot 0$, SD $8.0 \mathrm{~ms}$ for the biceps and $21 \cdot 3$, SD $7.0 \mathrm{~ms}$ for the thenar muscles on cervical stimulation. The shorter duration of the responses to brain stimuli in comparison with those to cervical stimulation is likely to be due to differences in the activation site. ${ }^{315}$ The average latency (table 2) and duration of responses to cervical stimulation was the same in multiple sclerosis patients and control subjects.

Cortical MAPs on the other hand, were abnormal in 20 out of 29 of the multiple sclerosis patients (table 1) (fig 2). To compare clinical and neurophysiological findings, the data from the patients were grouped according to the clinically involved arms. Table 2 includes arms with and without motor signs. Considering the multiple sclerosis patients as a group, CMCTs were significantly prolonged in comparison to normal subjects (table 2). Conduction delay was evident in the definite multiple sclerosis patients with motor signs, but attained significance also in the group without motor signs (table 2). In the group of non definite multiple sclerosis the difference from control values was not significant (table 2). In patients with definite multiple sclerosis and clinical pyramidal impairment of the upper limbs (table 1, cases 1-14) cortical MAPs were absent in two cases (bilaterally in case 3 and on one side in case 9L) and significantly delayed on both sides in the other 11 cases. In one case the cortical MAPs and consequently the CMCTs were normal (table 1, case 14). In five patients (table 1, case 9R, 10R, 11R, 12R, and 13L) abnormalities of CMCT were not accompanied by clinical involvement.

Conduction delay involved the cortex to biceps and cortex to thenar pathways together in 12 patients (table 1 , cases $1 \mathrm{~L}, 2,3,4,5 \mathrm{~L}, 7,8,9,10,11 \mathrm{~L}, 12 \mathrm{~L}$, and 14) and only the cortex to thenar pathway alone in two patients (table 1, cases 6,12).

In the five patients with definite multiple sclerosis but without pyramidal signs in the upper limbs (table 1, cases 15-20) electrophysiological abnormalities were present in four patients (cases 15, 16, 17, and 18). CMCT was delayed in both upper limbs in cases 15 , 16 , and 18 and only on one side in patient 17 .

Conduction delay involved both the cortex to biceps and cortex to thenar pathways in two cases (table 1 , cases 15 and 18) and only the cortex to thenar pathway in two patients (table 1 , cases 16,17). In case 17 the cortex to biceps pathway was not studied.

In the group with non definite multiple sclerosis only three patients had electrophysiological abnormalities (table 1, cases $21,22,23$ ). The delay was bilateral in case 21 and 23 and only on one side in case 22. Conduction delay involved both the cortex to biceps and thenar pathways in one patient (table 1, case 22)

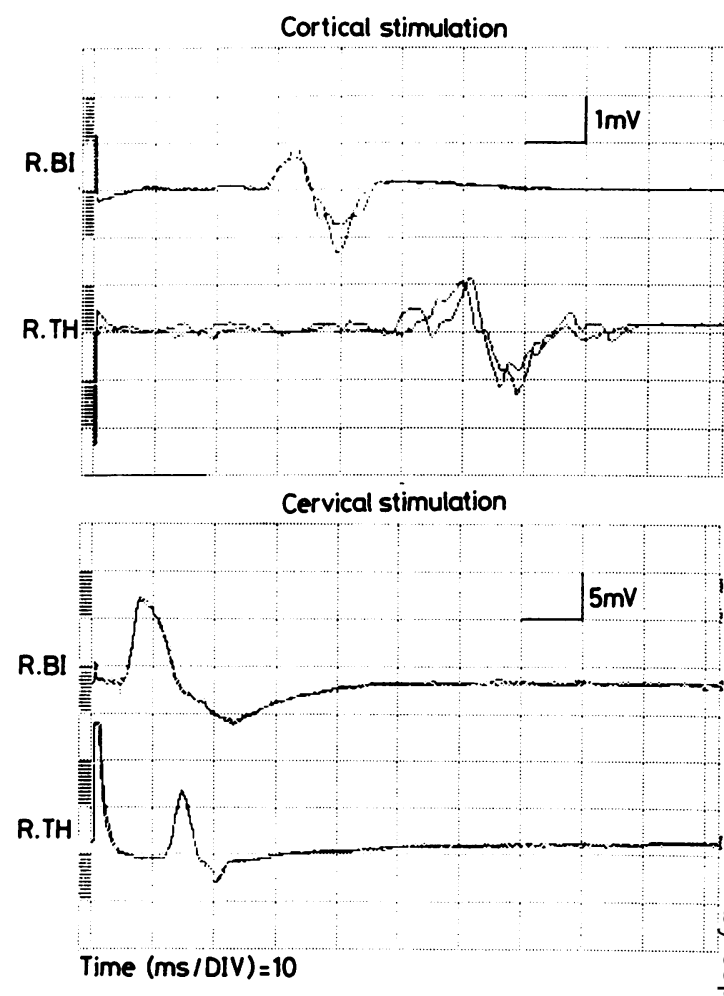

Fig 2 Muscle action potentials (MAPs) after cortical and cervical stimulation in a patient with multiple sclerosis. R.BI. (right biceps), R.TH. (right thenar). Superimposition of two single trials. Horizontal calibration $10 \mathrm{~ms} /$ div.

and the cortex to thenar pathway in two patients (table 1 , cases 21,23 )

Cortical MAPs were prolonged in at least one muscle, in 13 out of the 29 patients, and the CMCT to biceps and thenar muscles or both, was delayed.

\section{Somatosensory evoked potentials}

The Erb-point potential was present at a normal latency in all patients (table 3). The N13 component of the cervical potential was absent in 11 patients (table 1 , cases $1 \mathrm{~L}, 3 \mathrm{~L}, 5 \mathrm{~L}, 6,7,10,13,15 \mathrm{R}, 16,17 \mathrm{R}$, and 18 ) with definite multiple sclerosis and in two patients with non definite multiple sclerosis (table 1 , case 26 , 27L). The N20 cortical potential was absent in seven patients (table 1, cases 1, 5L, 7L, 15L, 16, 17R, and 18) with definite multiple sclerosis and in one patient with non definite multiple sclerosis (table 2, case 26). CSCT exceeded the normal range in nine patients with definite multiple sclerosis (table 1 , cases $3 R, 4$, 5R, 7R, 8L, 10R, 13, 14, and 15R). 
Table 3 Latency of Erb point, cervical and cortical potentials evoked by stimulation of median nerve

\begin{tabular}{|c|c|c|c|c|c|}
\hline & $n$ & $E r b$ & $N 13$ & $N 20$ & CSCT \\
\hline Controls & 30 & 9.5 SD 0.8 & $13 \cdot 0 \mathrm{SD} 0.5$ & $18 \cdot 3 \mathrm{SD} 1 \cdot 0$ & $9 \cdot 0 \mathrm{SD} 0.5$ \\
\hline Definite with motor signs & 19 & $9 \cdot 5 \mathrm{SD} 0.6$ & $\begin{array}{l}13 \cdot 1 \text { SD } 0 \cdot 7 \\
\text { abs in } 7\end{array}$ & $\begin{array}{l}19 \cdot 8 \text { SD } 1 \cdot 8 \\
\text { abs in } 6 \\
*\end{array}$ & $\begin{array}{l}10 \cdot 3 \text { SD } 1.9 \\
\text { not evaluable in } 6 \\
\text { * }\end{array}$ \\
\hline Definite without motor signs & 23 & $9 \cdot 2 \mathrm{SD} 0.6$ & $\begin{array}{l}13 \cdot 0 \mathrm{SD} 1 \cdot 0 \\
\text { abs in } 11\end{array}$ & $\begin{array}{l}19 \cdot 9 \text { SD } 2 \cdot 1 \\
\text { abs in } 4 \\
*\end{array}$ & $\begin{array}{l}10 \cdot 6 \mathrm{SD} 2 \cdot 1 \\
\text { not evaluable in } 4\end{array}$ \\
\hline Non definite & 18 & $9 \cdot 5 \mathrm{SD} 0.8$ & $\begin{array}{l}12 \cdot 9 \text { SD } 0 \cdot 6 \\
\text { abs in } 3\end{array}$ & $\begin{array}{l}18 \cdot 7 \mathrm{SD} 0 \cdot 7 \\
\text { abs in } 2\end{array}$ & $\begin{array}{l}9 \cdot 2 \mathrm{SD} 0 \cdot 3 \\
\text { not evaluable in } 2\end{array}$ \\
\hline All patients & 58 & $9 \cdot 4 \mathrm{SD} 0 \cdot 6$ & $\begin{array}{l}13 \cdot 0 \text { SD } 0 \cdot 8 \\
\text { abs in } 21\end{array}$ & $\begin{array}{l}19 \cdot 5 \text { SD } 1 \cdot 7 \\
\text { abs in } 12\end{array}$ & $\begin{array}{l}10 \cdot 0 \mathrm{SD} 1 \cdot 7 \\
\text { not evaluate in } 12\end{array}$ \\
\hline
\end{tabular}

CSCT: Central sensory conduction time.

$\mathrm{n}$ : number of examined arms.

*: statistical significance refers to difference between controls and each of the patient groups (Student's $t$ test).

$\mathrm{p}<0.01$.

To compare clinical and neurophysiological findings the data from the patients have been grouped according to the clinically involved arms. Table 3 includes arms with and without sensory signs. Considering the entire group of multiple sclerosis patients the latency of N20 and CSCT was prolonged in comparison with normal subjects. The N20 latency and the CSCT were significantly increased $(p<0.01)$ in both groups of definite multiple sclerosis. In the group of non definite multiple sclerosis (table 3) the difference was not significant. The average N13 latency and of the Erb-point potentials did not differ from control values, but it is worth emphasising that, in 11 patients, N13 could not be identified (table 3).

\section{Clinical and neurophysiological correlations}

Abnormalities of the cortical MAPs were found at least in one muscle in 17 patients with definite and in three with non definite multiple sclerosis. The rate of abnormality of cortical MAPs was therefore $85 \%$ in definite multiple sclerosis and $30 \%$ in non definite multiple sclerosis, while that of $\mathrm{N} 13$ and N20 abnormalities was $70 \%$ and $20 \%$, respectively. The overall rate of abnormality was $69 \%$ for motor, and $59 \%$ for sensory neurophysiological signs.

A correlation was found between the clinical and neurophysiological signs of motor impairment. Cortical MAPs were abnormal in $26(90 \%)$ out of 29 arms with pyramidal signs or weakness. Only cases $13 \mathrm{~L}$ and 24L (table 1) had clinical motor signs but normal neurophysiological data. The CMCT strongly correlated with the pyramidal signs $\left(\chi^{2}\right.$ test, $\left.\mathrm{p}<0.0005\right)$ and to a lesser extent with the weakness $\left(\chi^{2}\right.$ test, $p<0.05)$. A subclinical impairment of central motor conduction was demonstrated by abnormal cortical MAPs in 12 out of 27 upper limbs $(44 \%)$. The CMCT did not correlate with sensory symptoms and signs.

A lower degree of correlation was found between SEPs and clinical impairment of the sensory system. SEPs showed a weak correlation with sensory symptoms $\left(\chi^{2}\right.$-test, $\left.\mathrm{p}<0.06\right)$ and no correlation with sensory signs. A subclinical impairment of the sensory system was demonstrated by SEPs in 16 of 26 arms $(61 \%)$.

A correlation was also found between SEPs and pyramidal signs $\left(\chi^{2}\right.$ test, $\left.\mathrm{p}<0.05\right)$.

In 23 arms $(40 \%)$ cortical MAPs and SEPs were both abnormal. This finding of abnormal cortical MAPs together with normal SEPs occurred in 15 upper limbs and the opposite in $5(9 \%)$.

\section{Discussion}

In normal subjects scalp and cervical stimulation are easily tolerated. No side-effects or EEG changes have been reported in either healthy subjects or multiple sclerosis patients.

Cervical MAPs were normal in all our patients, this agrees with reports from Cowan et $^{\mathrm{al}} \mathrm{l}^{4}$ and Mills and Murray. ${ }^{5}$ Cortical MAPs, on the other hand, were abnormal in $85 \%$ of the patients with definite multiple sclerosis. As Mills and Murray ${ }^{15}$ have shown that cervical stimulation excites the motor roots at their exit from the spinal canal abnormal cortical MAPs indicate an impairment of central motor pathways. The abnormalities in our study consisted in absent or delayed and dispersed cortical MAPs, the rate and the type of abnormalities is consistent with previous reports of electrical stimulation of the motor cortex. ${ }^{45}$

It is difficult to compare the results obtained with the technique of bipolar electrical stimulation ${ }^{45}$ with those obtained using magnetic stimulation ${ }^{1314}$ in 
multiple sclerosis. Day et $a l^{16}$ and Hess et $a l^{17}$ have suggested that different neural structures are stimulated by the two techniques. Hence, a comparative study using electrical and magnetic stimulation in the same group of patients is necessary.

An abnormal central motor conduction has also been described in patients with motor neuron disease $^{8-10}$ and in patients with hemiparesis or hemiplegia due to hemispheral infarction. ${ }^{78}$ However, in these two conditions the cortical MAPs were more frequently absent. Since the cortical MAPs were absent only in two patients but were delayed and prolonged, or both, in 19 patients the most common abnormality in multiple sclerosis is a delay in central motor conduction.

Also, in patients with motor neuron disease or vascular hemiparesis ${ }^{7-10}$ the delay of cortical MAPs is usually of $2-3 \mathrm{~ms}$ only, while in our patients with definite multiple sclerosis the delay averaged $5-7 \mathrm{~ms}$ and in some cases reached $20-25 \mathrm{~ms}$. In multiple sclerosis the increase in latency and duration of cortical MAPs is probably due to slowing of conduction velocity of the largest diameter fibres to the pyramidal tract, owing to demyelination, as has been observed in experimental demyelination. ${ }^{18}$ However, the mechanism responsible for the delay and prolongation of cortical MAPs may be more complex. Evidence ${ }^{19}$ has been provided that in normal subjects a single cortical shock may produce multiple descending excitatory volleys which travel to the spinal cord, equivalent to the $\mathrm{D}$ and I waves recorded from the pyramidal tract fibres in animal experiments. As discussed by Thompson $e t a l^{8}$ "if the initial descending volley is reduced in size it may be unable to discharge the motoneurons without temporal summation with later arriving volleys. The time taken for this to occur would increase the central conduction time". This mechanism may explain delays in the central motor conduction and particularly delays of few milliseconds only. On the other hand "delay of the central motor conduction in excess of few milliseconds would indicate slowing of conduction in central pathways".

Abnormalities in corticomotoneuron conduction correlated with the clinical impairment of the patients. Cortical MAPs were abnormal in $90 \%$ of upper limbs with pyramidal signs or weakness and correlated strongly with pyramidal signs. Abnormalities of cortical MAPs were also present in $44 \%$ of arms without clinical signs of motor impairment. This finding demonstrates that with the technique of cortical stimulation it is possible to reveal clinically silent motor lesions.

We have confirmed that changes of the SEP are present in a large number of patients with multiple sclerosis and that these changes may be present even in absence of clinical sensory signs. ${ }^{20}$
Comparing the rate of abnormalities of motor and sensory neurophysiological signs we have seen that the cortical MAPs were more frequently abnormal than N13 and N20 components of the SEPs. Nevertheless, SEPs are useful. They allow a more precise localisation of the conduction defect, since alteration of the spinal (N13) potential may localise the damage at spinal level, while cortical MAPs results are equally abnormal whether demyelination takes place in hemispheral or spinal portion of the pyramidal tract. Subclinical abnormalities are more frequent for SEPs $(62 \%)$ than for cortical MAPs $(30 \%)$. Furthermore, neurophysiological abnormalities are more helpful in the sensory system, which provides less "objective" signs than the motor system.

Although cortical MAPs and SEPs were often both abnormal in the same patients, the two techniques can demonstrate abnormalities independently. We therefore believe that in studying patients with multiple sclerosis both techniques should be used.

\section{References}

1 Merton PA, Morton HB. Stimulation of the cerebral cortex in the intact human subject. Nature 1980;285: 227.

2 Merton PA, Hill DK, Morton HB, Marsden CD. Scope of a technique for electrical stimulation of humano brain, spinal cord, and muscle. Lancet 1982;2:597-600,

3 Rothwell JC, Thompson PD, Day BL, et al. Motor cortex stimulation in intact man; $I$. General character-? istics of EMG responses in different muscles. Brain 1987;110:1173-90.

4 Cowan JMA, Rothwell JC, Dick JPR, Thompson PD, Day BL, Marsden CD. Abnormalities in central motor pathway conduction in multiple sclerosis. Lancet 1984;ii304-7.

5 Mills KR, Murray NMF. Corticospinal tract conduction time in multiple sclerosis. Ann Neurol 1985;18:601-5.

6 Snooks SS, Swash M. Motor conduction velocity in the human spinal cord: slowed conduction in multiple sclerosis and radiation myelopathy. $J$ Neurol Neurosurg Psychiatry 1985;48:1135-9.

7 Berardelli A, Inghilleri M, Manfredi M, Zamponi A, Cecconi V, Dolce G. Cortical and cervical stimulation after hemispheral infarction. $J$ Neurol Neurosurg Psychiatry 1987;50:861-5.

8 Thompson PD, Day BL, Rothwell JC, et al. Motor cortex stimulation in intact man. Interpretations of electromyographic responses in disease of the upper motor neurone. J Neurol Sci 1987;80:91-110.

9 Berardelli A, Inghilleri M, Formisano R, Accornero N, Manfredi M. Stimulation of motor tracts in motor neurone disease. J Neurol Neurosurg Psychiatry 1987; 50:732-7.

10 Ingram DA, Swash M. Central motor conduction is abnormal in motor neurone disease. $J$ Neurol Neurosurg Psychiatry 1987;50:159-66.

11 Rossini PM, Di Stefano E, Boatta M, Basciani M. Eval- 
uation of sensory-motor "central" conduction in normal subjects and in patients with multiple sclerosis. In: Morocutti C, Rizzo PA (Eds) Evoked potentials, Neurophysiological and Clinical Aspects. Amsterdam, Elsevier 1985;115-30.

12 Rossini PM, Marciani MG, Caramia M, Roma V, Zarola F. Nervous propagation along motor pathways in intact man: characteristics of motor responses to bifocal and unifocal spine and scalp non invasive stimulation. Electroencephalogr Clin Neurophysiol 1985;61:272-86.

13 Hess CW, Mills KR, Murray NMF. Measurement of central motor conduction in multiple sclerosis by magnetic brain stimulation. Lancet 1986;ii:355-8.

14 Barker AT, Jalinous R, Freeston JA. Clinical evaluation of conduction time measurements in central motor pathways using magnetic stimulation of the human brain. Lancet 1986;i:1325-6.

15 Mills KR, Murray NMF. Electrical stimulation over the human vertebral column: which neural elements are excited? Electroencephalogr Clin Neurophysiol 1986; 63:582-9.

16 Day BL, Thompson PD, Dick JP, Nakashima K, Marsden CD. Different sites of action of electrical and magnetic stimulation of the human brain. Neurosci Lett 1987;75:101-6.

17 Hess CW, Mills KR, Murray NMF. Responses in small hand muscles from magnetic stimulation of the human brain. J Physiol 1987;388:397-419.

18 McDonald WI, Sears TA. The effects of the central demyelination on conduction in the central nervous system. Brain 1970;93:583-98.

19 Day BL, Rothwell JC, Thompson PD, et al. Motor cortex stimulation in intact man: II. Multiple descending volleys. Brain 1987;110:1131-1209.

20 Davis SL, Aminoff MJ, Panitch HS. Clinical correlation of serial somatosensory evoked potentials in multiple sclerosis. Neurology 1985;35:359-65. 